\title{
Study on Application of Building Waterproof Construction Technology Fuyong Huang ${ }^{1}$ \\ ${ }^{1}$ Liaoning Jianzhu Vocational University, Liaoyang, Liaoning, 111000 \\ 73691468@163.com
}

Keywords: Waterproof Technology; Building Construction; Application Aspects

\begin{abstract}
This paper raises the question of the status of the building waterproofing and the facing technical route background and significance of the research, content and research. On the basis of the current problems in the domestic construction waterproofing industry development and management analysis on the whole, the whole process of building water projects form the basis of the key factors controlling system, it pointed out that construction waterproofing quality depends on the quality of materials, design quality, process quality, construction technology level, workers operating level, product level protection, construction management and other factors.
\end{abstract}

\section{Introduction}

Building waterproof construction engineering project is an important part of building waterproof technology is to ensure that the structure of buildings and structures from the invasion of water, content space from water hazards specific measures and a subpart. Specifically, it refers to water in order to prevent rainwater, production or domestic water, groundwater, stagnant water, capillary water and hydro-geological changes caused by human factors arising penetrate buildings, structures or to prevent internal leakage out of the water storage project take a series of structures, construction and building measures. Generally speaking, water projects including external water to prevent water penetration inside the building, outside the building water leakage and water within the structure, the internal structure of mutual sealing three parts. Its function is to make buildings or structures within the design durable life, prevent all types of water erosion, ensure that the building structure and interior space without fouling, for people to provide a comfortable and safe living environment.

Building leakage problem is more widespread building quality defects. Many roof leaks, the walls leak, paint coating off phenomenon, day after day, the roof, inside walls due to leak out of the area now flaking and damp due to leakage caused by long moldy taste, a direct impact on household health, not to mention the indoor decoration. Office, computer room, workshop and other work places such as long-term leak will seriously damage the office facilities, precision instruments and machine tools, etc. can also cause birth mildew and failures, and even cause a short circuit. Faced leakage, every few years people will have to spend a lot of manpower and material resources to carry out the repair. Leakage not only disrupts people's normal life, work, production order, but also directly affect the life of the whole building. Thus building waterproof effect is good or bad, is critical to the quality of the building, so that the water projects occupy a very important position in construction throughout the building construction, we must be strictly and conscientiously do a good job of building waterproof engineering .

\section{Problems Existing in Building Waterproof Engineering}

Architectural Engineering easy to produce water leakage site are: roof parts, interior parts (especially toilet and bath, kitchen and balcony seepage water, water drains, vanities, toilets, sinks and other sanitary facilities, dripping water, etc.), external wallboard joints parts (including outer walls, steel windows and aluminum window, window frame beam bottom, side columns, etc.), the basement floor and walls and other parts.

The main factors leading to the leakage of construction projects are: 
Material issues: such as waterproof material quality is not satisfactory, not up to standard requirements, or the existence of mixed fish head waterproof material, mixed conditions, or shoddy products, poor quality, construction technology and some material to be mature;

Design problem: waterproof fortification unreasonable, such as the temperature difference between the roof stretching deformation member is no corresponding control methods, some of the improper selection of waterproof material design, some water treatment without supporting technology, but also part of the design detail detailed construction drawings without watertight structure Wait;

Construction problems: construction of low-skilled, some construction managers paid insufficient attention to building waterproof, waterproof construction of the building without technology programs and technical measures, primary treatment to poor water, approach the material most unchecked, inspection and control, construction workers low technical quality, but not waterproof operation process and no construction experience and the like;

Management problems: improper use of the building management, if the user to arbitrarily change the building structure, a hole leading to the installation of various equipment waterproof layer destruction. As construction projects engineering products, investment and cost of labor, materials and energy are quite large, if the poor quality of the project will not be able to play its due effect, but also because of the quality, safety and other issues affecting the security of people's livelihood and social environment. Because water causes major construction projects have serious quality problems or quality defects, not only difficult to make up, and huge losses. And how to improve and ensure the quality of construction of water works will inevitably become a topic worthy of serious study.

\section{Building Waterproof Classification and Waterproof Control Technology}

Waterproof construction projects can be based on fortified position, fortification method, material properties and fortification used to classify species.

Civil engineering is classified by categories: waterproofing of buildings and structures can be divided into watertight.

Press fortified parts of the classification: According to the basic structure and each member plays the role of housing construction, according to the buildings and structures engineering fortified site can be divided into the ground waterproofing works and underground works. Ground water projects including roofing projects, wall waterproofing and ground water projects. It refers to the building of underground basements, underground trench, underground railways, tunnels and other structures waterproofing.

The method according to fortification Category: fortification methods can be divided according to a composite waterproof and constructed from waterproof. Composite waterproof refers to using a variety of waterproof materials a waterproof new waterproof approach. Using a variety of different properties of waterproof material in fortification, using each having a characteristic, the composite used in the waterproofing works, take advantage of a variety of waterproof materials, in order to improve the overall performance of water works, so that "rigid-flexible, multi-channel fortification, comprehensive management. " Constructed from waterproof is the use of some form or method constructed from a waterproof or water drainage combined approach. Such as subway stations to prevent seepage sidewall spacers using double wall lining (shrinkage-compensating concrete waterproofing), induced joints and back roof structure to prevent cracks and set up pouring belt.

By species classification fortification materials: waterproofing materials fortified by species can be divided into: waterproof membrane, waterproof coating, sealing materials, waterproofing, concrete and cement mortar waterproof, waterproof plastic plates, metal plates and waterproof.

Press material properties fortification Category: fortification materials according to the performance of the classification can be divided into rigid waterproof and flexible waterproof. It refers to the use of rigid waterproof concrete and mortar for waterproof layer. Flexible waterproof means do it the role of a flexible waterproof material, such as waterproofing membrane, applied waterproof layer. 
Water Proofing in House Wall. Roofing screed easy to crack, to prevent them, we need to set up sub-lattice seam on the leveling layer. When waterproof construction, waterproof layer of 200mm wide additional layer laid on the sub-lattice seam, unilateral pasted on which to do the waterproof layer. When the roof slope less than 3\%, the web should be parallel to the roof paving; roof slope at $3 \%$ to $15 \%$, the web may be parallel or perpendicular to the roof paving; roof slope greater than $15 \%$, or subject to vibration, the web Stones should be perpendicular to the ridge. When the waterproof layer construction, should first make node, additional layers and parts of the roof drainage is relatively concentrated. (Roof and fall-port connections, eaves, gutters, gutters, roofing around the corner, the board side seam, etc.). Paving Gutter, gutters when the web, should Sunchon ditch, eaves direction, reducing overlap. Paving multi-span and high and low across the roof, should be first high to low, the first distant past order. Stones roll method using the lap, on the lower and adjacent two coil lap joints should be staggered. Parallel to the ridge of the lap joint along the flow direction should lap, at the junction of the gutter and the roof should overlap cross connection, measures should be taken to prevent the decline in the web at the overlap.

In order to prevent the phenomenon pouring rainstorm, the first sealing material fall-port connections and standpipe socket were filling them dense. Fall-mouth can be divided into straight type and wall row, but no matter what form additional waterproof layer should be around 500mm within.

Construction Technology of Underground Works Waterproof. Waterproof cushion on the floor in the general building structure empty shop law, point bonding method, sticky strip and mechanical fixation. However, in order to better control the quality of underground water projects, empty shop law is more appropriate. Waterproofing membrane lap process should be carefully, if not done overlapping parts detail treatment, the adhesive is not strong, the future will always be underground leakages. Underground waterproofing membrane process in lap, lap length of its side should be controlled at between $90 \mathrm{~mm} \sim 100 \mathrm{~mm}$, to prevent hollowing phenomenon, waterproofing membrane at the edge should be thoroughly drained of air infiltration, sealing position require extrusion melt asphalt.

Construction can be protected by a wall of masonry permanent way, first empty Laying additional layer of waterproofing membrane, and then do a layer of waterproofing membrane on the additional layer, using the full bonding method between two layers of waterproofing membrane. In the structure of the first floor level position Jiecha thrown coil length, usually not less than 300mm, and take a virtual puzzle 3 leather casing or brick way for waterproofing protection. Rear floor construction is completed, the rejection of stubble waterproofing membrane surface clean, then carried to the upper waterproofing membrane lap, lap length is not less than $100 \mathrm{~mm}$.

Underground wall waterproofing should focus on the degree of firm walls and waterproofing membrane paste, waterproofing membrane during the construction of the wall, you should use full-paste approach. This can effectively prevent the web after pasting finished, because of its internal voids caused by the presence of air or water leakage off the web. After pouring with water is the key to the construction of the underground wall waterproofing, if inappropriate measures will have a significant impact on water quality of the whole façade. Can be used in parts of Canada set back strip precast reinforced concrete decking way, the waterproof material construction on the cover, so that the waterproof layer to form a whole.

Bathroom Floor Waterproofing Technology. Set up concrete barriers in the bathroom threshold position, its height is generally controlled at about $75 \mathrm{~mm}$, its width is consistent with the width of the wall, in order to warm the collaborative construction, should set two suitable grooves thereon, for its use to warm the pipe. Bathroom threshold area should first make negative angle and rounded recess, after the threshold is done, the water lapping onto the sill, so as to form a closed waterproof layer. In addition to the pipeline should also address the roots out of the ground water within good bathroom, first laid on the good level of waterproof canvas processing pipeline, to prevent pipeline breaks, then do waterproofing reinforced layer again.

The main reason is there is leakage through the floor and wall of the pipe, floor drain and other loose, smoke duct sink, tear waterproof layer. Since other parts of the root canal loose or adhesive is 
not strong, the contact surface cleaning is not clean voids, seal lap length is not enough, paste does not close, may damage the waterproof protective layer waterproof layer, the first water test water depth not enough and so on. Therefore, the requirements in the construction process, the relevant processes should seriously operate in strict accordance with process standards and construction specifications for construction. After the waterproof layer construction, for the first time water test, water depth must be higher than the standard $20 \mathrm{~mm}$, 24h no leakage in compliance. After construction of the ground surface, and then a second water test, 24h no leakage in final qualifying, fill water inspection report. Ground water after the second test, has acceptance, but still found after the completion of the use of leakage, mainly because of the plumbing fixture drain pipe socket is not connected tight, not building sealant After connection, or after security sanitary ware fixing screws penetrating waterproof layer without processing.

\section{Conclusion}

Waterproofing works belongs to key projects and hidden in the building construction and can ensure the quality of the project to play an important role. Although can have much improved, the current Waterproof construction technology can not meet the requirements of the development of water projects. Waterproof construction technology is a comprehensive, practical strong engineering technology, able to master and apply it to practice, it improve the life of the building, ensure the building from erosion and improve the living environment from the a crucial role.

\section{Acknowledgements}

Project Name: construction engineering management professional production and teaching combined with the training mode of talents

Project level: Liaoning Province Vocational Technical Education Institute of scientific research planning project

Project number: LZY15561

\section{References}

[1] Sriprasert E and Dawood N. Multi-Constraint Information Management and Visualisation for Collaborative Planning And Control in Construction, 2003.

[2] Z. M. Deng, H. Li, C. M. Tam, Q. P. Shen, P. E. D. Love, An Application of The Internet-based Project Management System, Automation in Construction

[3] Devingrant. Quality Management in Us Higher Education. Total Quality Management. 2002(2): 207.

[4] Karaszewski Robert. Quality Management and the World's Largest Corporations. Quality Progress.2003.9,No. 